\title{
PLANAR PACKINGS AND MAPPINGS RELATED TO CERTAIN MINMAX PROBLEMS
}

\author{
SEON-HONG KIM
}

Abstract. For any integer $N \geqslant 1$, we obtain the extremal values of the minmax problem for exponential sums,

$$
f(N):=\min _{a_{i} \text { real }} \max \left\{\left|\sum_{n=1}^{N} e^{i a_{n}}\right|,\left|\sum_{n=1}^{N} e^{i N a_{n}}\right|\right\} .
$$

In particular, the two extremal problems $f(3)$ and

$$
\max _{a, b, c \in[0,2 \pi]} \min \left\{\left|\left(e^{i a}-e^{i b}\right)\left(e^{i b}-e^{i c}\right)\left(e^{i c}-e^{i a}\right)\right|,\left|\left(e^{i 3 a}-e^{i 3 b}\right)\left(e^{i 3 b}-e^{i 3 c}\right)\left(e^{i 3 c}-e^{i 3 a}\right)\right|\right\}
$$

are reduced to the problems about the packing of certain convex sets in the plane. This packing method also can be used to solve some other extremal problems.

Mathematics subject classification (2000): 52C15; 05B40.

Key words and phrases: packing, convex, Jacobian, lissajous figure, minmax.

\section{REFERENCES}

[1] N. G. DE BRUIJN, On the factorization of cyclic groups, Indag. Math. 15 (1953), 370-377.

[2] J. H. CONWAY, A. J. JONES, Trigonometric diophantine equations (on vanishing sums of roots of unity), Acta Arith. 30 (1976), 229-240.

[3] P. Erdös, P. M. Gruber, J. Hammer, Lattice points, Pitman Monographs and Surveys in Pure and Applied Mathematics, vol. 39, Longman Scientific \& Technical, Harlow; copublished in the United States with John Wiley \& Sons, New York, 1989.

[4] L. Fejes Tóth, Regular figures, Pergamon Press Book, The Macmillan Co, New York, 1964.

[5] H. Hadwiger, H. Debrunner, Combinatorial geometry in the plane, Translated by Victor Klee. With a new chapter and other additional material supplied by the translator Holt, Rinehart and Winston, New York, 1964.

[6] János Pach, Pankaj K. Agarwal, Combinatorial geometry, John Wiley \& Sons, Inc., New York, 1995.

[7] T. Y. LAM, K. H. LeUNG, On vanishing sums of roots of unity, J. of Algebra 224 (2000), 91-109.

[8] H. W. Lenstra, JR., Vanishing sums of roots of unity, Proceedings of the Bicentennial Congress Wiskundig Genootschap, Vrije Univ. Amsterdam, Amsterdam, 1978; Part II, Math. Centre Tracts, 101, Math. Centrum, Amsterdam, 1979, pp. 249-268.

[9] H. B. ManN, On linear relations between roots of unity, Mathematika 12 (1965), 107-117.

[10] S. PINCHUK, A Counterexample to the strong real Jacobian conjecture, Math. Z. 217 (1994), 1-4.

[11] I. J. SchoenBerg, A note on the cyclotomic polynomials, Mathematika 11 (1964), 131-136.

[12] T. STORER, Cyclotomy and Diffence Sets, Markham, Chicago, 1967. 